\title{
ON THE STANDARD-WATER USED IN THE HYDROGRAPHICAL RESEARCH UNTIL JULY 1903
}

\author{
BY
}

\section{MARTIN KNUDSEN}

\begin{abstract}
$\mathrm{A}^{\mathrm{T}}$ the international conference for the exploration of the sea, held $A$ in stockholm 1899, I laid before the conference a printed "proposal about an international institution for procuring standard-water". (Reprinted in "Conférence internationale pour l'exploration de la mer, réunie à Stockholm 1899“, page XLII, Supplément 4).

As will be seen in that paper my opinion was, that the main duty of a hydrographical central laboratory should be to procure standard-water in order to secure homogeneity in the determinations of halogen done by the different nations. The plan was not adopted in its whole extent by the conference, only a remark about standardwater was taken up in the hydrographical program, worked out by a committee of the conference and agreed upon by the latter.

Then Professor FridtJof NANSEN proposed the erection of a central laboratory for the undertaking" of various important investigations of general interest for the hydrographical and biological researches etc. (l. c. page 22, Appendix 2) and took up in this proposal, that standardwater should be provided by the laboratory.

When I, through the Stockholm conference was charged with the task of undertaking an experimental revision of certain hydrographical tables, I thought for the following reasons it would be right at the same time to make an attempt at procuring standard-water.

1) Though, in my opinion, the members of the Stockholm conference did not clearly see the advantage of using a standard-water for all titrations, I did not hear a single remark against it, and I myself felt convinced, that standard-water soon or later would be a great advantage, perhaps a necessity for cooperative hydrographical work.
\end{abstract}


2) It did not seem probable to me that the whole international cooperation would begin within a short time (experience has shown, that it took three years) and in the meantime it would be useful to have at hand reliable standard-water.

3) The researches done for the determination of the constants of different kinds of sea-water would offer a convenient occasion for determining the constants of standard-water.

4) In the case I should succeed in carrying through the work of the constants-determination and have compiled some hydrographical tables that could be generally adopted, I thought it of importance that the standard-water used should be investigated with the same means and methods as used in the researches upon which the tables would be founded.

Before the Stockholm conference took place, I made five different sets of standard-water and used them for the Danish hydrographical research, and so the standard-water prepared at the same time as the constant-determinations received the designation No. VI.

The water used for the standard-water No. VI was collected in bottles of green glass (see: „Berichte über die Konstantenbestimmungen zur Aufstellungen der hydrographischen Tabellen von GarL Forch, Martin Knudsen und S. P. L. Sørensen. Gesammelt von Martin Knudsen, D. Kgl. Danske Vidensk. Selsk. Skr., 6. Række, naturvidensk. og mathem. Afd. XII. 1. Pag. 22") and filtered through filter-paper (acido hydrochlorico et fluorico extracta). The water was taken up in the open Atlantic between the Færøes and Iceland. In the laboratory the water was poured into a well cleaned acid balloon of green glass. Through the cork went two glass tubes of which one reached the bottom and the other only went through the cork. The cork then was bound to the neck of the balloon and sealed to keep the latter airtight. The balloon was shaken in order to mix the water, and by means of a small caoutchouc pump the air in the balloon was compressed in order to make the water flow out through the glass tube that went to the bottom of the balloon.

According to my knowledge of the state of the various hydrographical methods, at the time of the constant-determinations, I thought it reasonable to use the standard-water as standard for the determinations of chlorine only, and as very few researches had been made concerning the influence of sea-water upon the different kinds of glasses, I thought the best plan would be to use the glass tubes I could get in the easiest way. From the Danish hydrographical researches I had some tubes $(250-300 \mathrm{cc}$, of the ordinary form of evacuated tubes), that had been used for gas-analyses. 
The ends of these tubes were drawn out and cut off as shown in the fig. 1 . The tubes were carefully cleaned with potassic hydrate, sulphuric acid and hot distilled water, and dried by warming up and passing through them a slow current of filtered air, dried in sulphuric acid. 8 of the tubes were put into a wooden stand as shown in fig. 2 . "The tubes passed through holes in the list $a a$ and the narrower ends of the tubes went through the holes in the list $b b$, and below that they were connected by small tubes of india rubber with the lateral tubes of the glass tube $c c$. Again this tube was connected with the glass tube that went through the cork to the bottom of the balloon containing the seawater. Thus the water

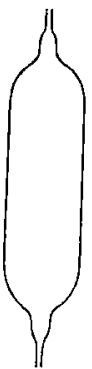

Fig. 1. was pressed up into the tubes, and when one of them was almost filled the indiarubber tube at the lower end of it was clamped and the upper end of the tube was sealed by means of a very hot gasflame from a blowpipe. As the sealing took a very short time and as the flame was very pointed and the upper part of the standard-

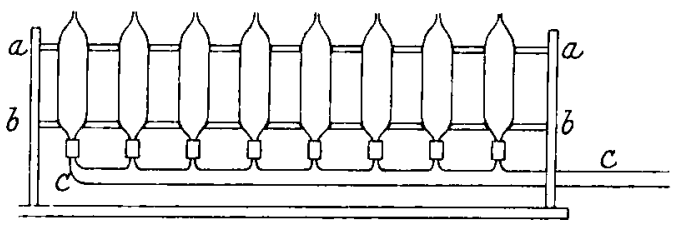

Fig. 2.

water tube dry, very little of the water could evaporate during the sealing. Then the filled tube was taken out of the stand and replaced by an empty one, that was now filled, and so on.

The filled tube was turned up and down and put into another stand, where the end, that now was the upper, was sealed in the same manner as mentioned in the foregoing.

During this sealing a small portion of the water will evaporate, but when the tube has been standing a short time before the sealing, the water layer in the tube covering the uppermost part of the glass has grown very thin and thus very little will evaporate. Another circumstance that possibly could involve greater error is, that water from the flame can be condensed into the tube, or the flame possibly can generate currents of air through the narrow tube and thus alter the amount of water in it. By the sealing great care therefore was taken always to keep the flame in the same position on the tube and always to use a flame of the same size and strength. 
When both ends of the tube were sealed a label with a number was pasted on the tube, that it could afterwards be seen in what order the filling and sealing had been done. One person did the first sealing, another person managed the clips and replaced the tubes when filled and sealed, a third person did the last sealing, a fourth person carried off the tubes and labelled them when they were ready, and shook the balloon with sea-water in order that the concentration should not be altered by distillation of the water.

About 80 tubes were filled with standard-water No. VI on April $11^{\text {th }} 1900$, and afterwards the investigation of the water from some of the tubes was undertaken. One Volhard's titration gave the amount of chlorine: 19,3798\% and two weight analyses gave 19,3782\% and 19,3796 \% ( „Berichte über die Konstantenbestimmungen ..." Pag. 105). The last decimal was thrown away and the amount of chlorine stated as $19,380 \%$. For the sake of control and to see how the specitic gravity changes in the tubes, 5 determinations of the specific gravity were made at different times as stated in the following table:

$\begin{array}{ccc}1900 & \text { April } 11^{\text {th }} & \text { the tubes were sealed. } \\ " & \text { June } 30^{\text {th }} & \sigma_{0}=28,142 \\ " & \text { Sept. } 9^{\text {th }} & \sigma_{0}=28,143 \\ " & \Rightarrow 11^{\text {th }} & \sigma_{0}=28,148 \\ 1902 & \text { Aug. } 17^{\text {th }} & \sigma_{0}=28,146 \\ & \sigma_{0}=28,157\end{array}$

(Partly to be seen in: "Berichte über Konstantenbestimmungen ..."

Pag. 73).

As the determination of the third decimal in $\sigma_{0}$ is quite reliable, it will be seen that the specific gravity is increasing with the time, and from the determination made 1900 Sept. $9^{\text {th }}$ in comparison with the others it will be seen that the different tubes are not all affected in the same degree by the sea-water. If $\sigma_{0}$ is calculated from the chlorine $19,380 \%$ by means of the formula in the hydrographical tables we get $\sigma_{0}=28,135$. Supposing that this is the original value of $\sigma_{0}$, this quantity in the last mentioned tube has increased to 28,157 during $21 / 2$ years. The difference 0,022 would arise if $0,022 \mathrm{gr}$. salt has been dissolved into 1 liter sea-water without change of volume. If the content of a tube is estimated at $1 / 4$ liter the quantity of salt dissolved has been $5,5 \mathrm{mgr}$. If the inner surface of the tube be estimated at $300 \mathrm{sq}$. $\mathrm{cm}$., the amount of salt dissolved from each square decimeter has been 1,8 mgr. For the sake of comparison may be mentioned, that Emanuel PFeiffer found the dissolved amount of glass in 154 days at $20^{\circ} \mathrm{c}$ to be between $1 / 2$ and $3 \mathrm{mgr}$. for each 
square decimeter (Annalen der Physik und Chemie, Bd. XLIV, 1891. Pag. 254), and F. Kohlrausci found the dissolved amount in 160 days to be 1,19 mgr. for each square decimeter (Annalen der Physik und Chemie, Bd. XLIV, 1891. Pag. 584). So far as I am aware, the glass they have used is similar to the kind of glass used for the standardwater tubes.

As might be expected the quantity of glass dissolved in the standard-water makes the specific gravity determination to be of very little use when carried out after the sealing of the tube. Under the supposition, that the glass does not contain any chlorine the dissolved glass will only affect the determination of chlorine with about half a unit in the third decimal place of chlorine per mille; for instance, a water that originally contains $19,380 \%$ chlorine will after the solution of $22 \mathrm{mgr}$. glass in one liter, give $(19,380-0,0004) \%$, by a weight determination of chlorine, provided that the solution of glass does not alter the volume of water in which it is dissolved.

From May 1900 to August 1902 the standard-water No. VI was used for all the Danish titrations, but most of the tubes were sent to different countries and used for the titrations there. Thus tubes have been sent to Russia, Sweden, Norway, Finland and Germany.

In the summer 1909 very few of these tubes were left, and as the international cooperation was then to begin, I was requested to procure a new supply of standard-water. Having expected this request, I was prepared and had the necessary water for the filling of the tubes. The water was collected in green glass bottles between the Færøes and Iceland. The tubes were altered in so far as a capillary tube of about $1,2 \mathrm{~mm}$. diameter and a length of $5 \mathrm{~cm}$. was fused to each of the ends of the tubes; the capillary tubes were drawn out to make the glass wall thin without making the tubes narrower. The idea in this alteration was to leduce the inner surface from which the water evaporated during the sealing and especially to prevent and diminish the air current through the tube, produced by the flame.

On August 12th 1902, 201 tubes were filled and sealed in the same manner as used for No. VI. The amount of chlorine was determined by Magister Niels Buerrum in the tubes No. 1,101 and 201. Volhard's titration method was used and as the water No. VI was used as standard, the new set got the designation:

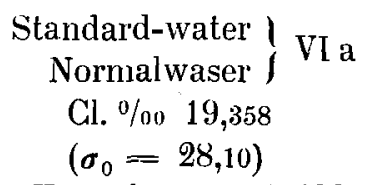

Kopenhagen $20 / 81909 . \quad \mathrm{Nr}$. ......... 
The results of the chlorine determinations are stated in the following table:

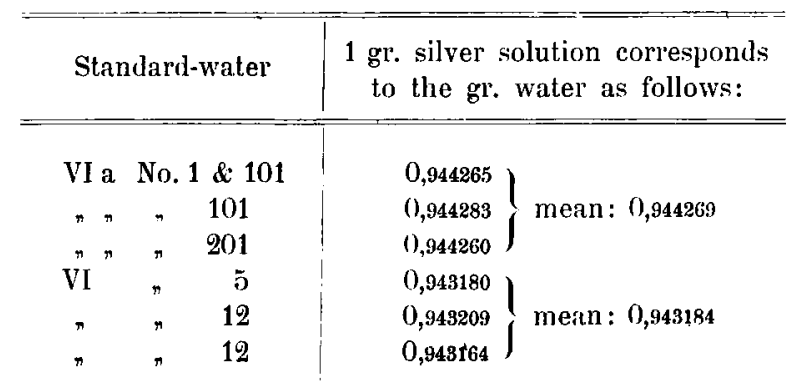

The amount of chlorine then will be $19,380 \cdot \frac{0,943184}{0,94269}=19,3577$, which is rounded to $19,358 \%$.

For the sake of control, determinations of the specific gravity were made by Magister H.J. HANSEN as stated below.

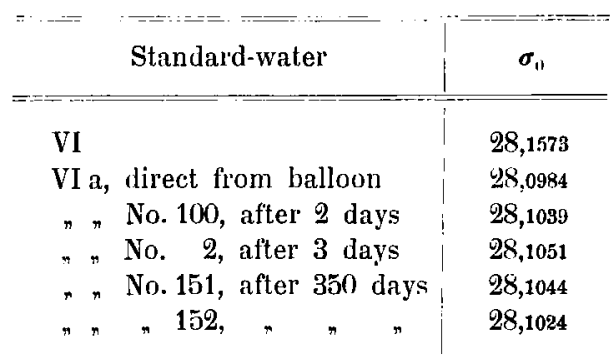

The chlorine of the water VI a when taken up from the sea was $19,50 \%$, and as it is necessary, that it should not differ by more than about 0,05 from 19,38 it was diluted with distilled water to the amount of chlorine as stated above (see: „Berichte über die chemische und physikalische Untersuchung des Seewassers und die Aufstellung der neuen hydrographischen Tabellen von Martin Knudsen, Carl Forch und S. P. L. Sørensen" in "Wissenschaftliche Meeresuntersuchungen, herausgegeben von der Kommission zur Untersuchung der deutschen Meere in Kiel und der biologischen Anstalt auf Helgoland. Abteilung Kiel. Neue Folge. Band 6“. Pag. 163).

Five of the tubes VI a were used for the determination of chlorine and specific gravity, and up to the present time $\left({ }^{18} / 6\right.$ 1903) the tubes have been sent out to the different countries, asking for them, as stated below: 


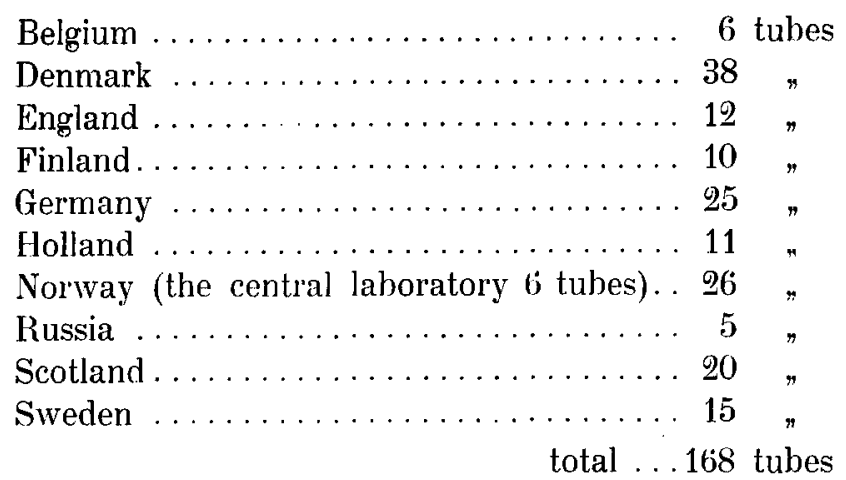

This standard-water has been procured and distributed at the cost of the International Council for the study of the sea: in accordance with the views of the general secretary, Dr. P. P. C. Hoek, the tubes have been forwarded free of cost to the laboratories of the different countries.

At the first and second meeting of the International Council for the study of the sea it was determined, that the Central Laboratory in Christiania should in future be responsible for the standard-water. In February 1903 about 100 of the tubes had been sent off and at that time I told the director of the laboratory Professor FridTJoF Nansen so, and now he has taken the matter in his hands. 